Agr. Biol. Chem., 40 (3), 593 597, 1976

\title{
Effects of Addition of Sulfur-containing Amino Acids and Their Catabolites to a Low Protein Diet on Liver Fat Content in Rats
}

\author{
Toshizo Kimura and Akira Yoshida \\ Laboratory of Nutritional Biochemistry, Department of Agricultural Chemistry, \\ Nagoya University, Chikusa, Nagoya, Japan \\ Received October 24, 1975
}

\begin{abstract}
To investigate the effects of catabolites of sulfur-containing amino acids on the liver fat content, rats fed a protein-free or $10 \%$ casein diet were orally or intraperitoneally administered sulfur-containing amino acids and their catabolites. Force-feeding of the proteinfree diet supplemented with 0.01 and $0.05 \%$ methionine reduced the excretion of urinary nitrogen, but it did not affect the liver fat content. Supplementation with $0.2 \%$ methionine induced significant liver fat accumulation accompanied with remarkable increases in the concentrations of nonprotein sulf hydryl (NP-SH) and taurine in the liver. The effects of the addition of $0.2 \%$ cystine $\mathrm{HCl}$ to the protein-free diet were similar to those of $0.2 \%$ methionine. Forcefeeding of the protein-free diet supplemented with $0.2 \%$ cysteine sulfinic acid or $0.2 \%$ thiopyruvate did not bring about any changes in the concentrations of sulfur-containing metabolites and fat content in the liver and the excretion of urinary nitrogen. On the contrary supplementation with $0.2 \%$ hypotaurine remarkably increased the liver fat content and taurine concentration without any changes in NP-SH concentration. The effects of injection of methionine, cysteine and hypotaurine to rats fed $10 \%$ casein diet on the fat content and sulfurcontaining metabolites in the liver were similar to those of oral administration of these compounds. These findings supported the possibility that the excess of catabolites of sulfurcontaining amino acids might be one of the factors which cause the liver fat accumulation.
\end{abstract}

A number of studies ${ }^{1 \sim 4}$ have shown that feeding rats on a low casein diet supplemented with sulfur-containing amino acids caused the liver fat accumulation, which was eliminated by the further addition of threonine to the diet. A little attention, however, has been payed which one of the sulfur-containing amino acids or their metabolites was the primary factor affecting the liver fat content. Previous study ${ }^{53}$ in this laboratory demonstrated that forcefeeding of a protein-free diet supplemented with sulfur-containing amino acids for several days produced a significant fat accumulation in the liver. And under the feeding condition the effects of addition of sulfur-containing amino acids and the other amino acids to the protein-free diet on the fat content and free amino acid concentrations in the liver, and the excretion of urinary nitrogen were also investigated. These experimental results suggested that the excess of some catabolites of sulfur- containing amino acids might be one of the factors which caused the liver fat accumulation. Recently we explored the relationship between changes in concentrations of some sulfur-containing metabolites and those in the liver fat contents of rats fed ad libitum low protein diets consisting of heated soybean flour, casein or wheat flour with or without added methionine, cystine, lysine or threonine. These results suggested that significant increase in the concentrations of liver nonprotein sulfhydryl (NP-SH) and taurine of rats fed a low protein diet supplemented with sulfur-containing amino acids might be a reflection of the excess of dietary methionine or cystine, resulting in the liver fat accumulation. ${ }^{6)}$

The purpose of this study was to investigate the possibility that the excess of some catabolites of sulfur-containing amino acids might be one of the factors which caused the liver fat accumulation. For this purpose some cata- 
bolites of sulfur-containing amino acids were orally or intraperitoneally administered to rats fed on a protein-free or low casein diet. And the effects of these catabolites on the concentrations of NP-SH and taurine, and fat content in the liver and the excretion of urinary nitrogen were studied.

\section{MATERIALS AND METHODS}

\section{Animals and diet}

Male rats of the Wistar strain were housed individually in screen bottom cages in temperature at $24^{\circ} \mathrm{C}$ with 12-hr cycle of light and dark. In experiments of forcefeeding, experiments 1 and 2, the composition of the protein-free diet, was as follows: as a percentage by weight; corn oil, 5 ; salt mixture, ${ }^{7)} 4$; vitamin mixture, ${ }^{53}$ 2; choline chloride, 0.1 ; and sucrose, 88.9. And $2500 \mathrm{IU}$ of retinyl palmitate, $250 \mathrm{IU}$ of ergocalciferol, and $5 \mathrm{mg}$ all-rac- $\alpha$-tochopherol were added to $100 \mathrm{~g}$ of the diet. For tube-feeding, the experimental diets were homogenized with water in a blender to make $70 \%$ $(w / v)$ homogenate. The suspended diet was force-fed three times daily at $4-\mathrm{hr}$ intervals. In experiment 3 , all rats were administered $10 \%$ casein diet, which contained, as a percentage by weight: casein 10.0 ; corn oil, 5; vitamin mixture, ${ }^{\text {b) }} 2$; salt mixture, $\left.{ }^{7}\right)$; choline chloride, 0.2 ; and sucrose; 78.8. Retinyl palmitate, $2500 \mathrm{IU}$; ergocalciferol, $250 \mathrm{IU}$; and all-rac- $\alpha$-tochopherol, $5 \mathrm{mg}$, were added to $100 \mathrm{~g}$ of the diet.

\section{Experimental procedure}

Experiment 1. The purpose of this experiment was to observe the effects of different amounts of methionine added to the protein-free diet on the concentration of nonprotein-sulfhydryl and taurine, and fat content in the liver, and the excretion of urinary nitrogen. Rats weighing approximately $120 \mathrm{~g}$ were used. They were force-fed a $10 \%$ complete amino acid diet ${ }^{5)}$ for several days to accustom to the procedure of force-feeding. For 4 days after this period all rats were subjected to force-feeding of the protein-free diet before the beginning of force-feeding of the experimental diets. Experimental diets were the protein-free diet supplemented with either $0.01,0.05$ or $0.2 \%$ L-methionine. The daily feed administration was $9 \mathrm{~g}$. Rats were killed $3 \mathrm{hr}$ after the first administration on the 5th day of the experimental feeding period. The liver was immediately removed and used for analysis. Urine was collected from animals, which were maintained in individual cages for 2 days during the latter half of the experimental period.

Experiment 2. The object of this experiment was to investigate the effects of addition of cysteine-cata- bolites to the protein-free diet on the concentration of nonprotein-sulfhydryl and taurine, and fat content in the liver and the excretion of urinary nitrogen. The experimental procedures were carried out basically as in experiment 1, except for the experimental diets. They were the protein-free diet supplemented with either $0.2 \%$ hypotaurine, $0.2 \%$ cysteine sulfinic acid $\mathrm{H}_{2} \mathrm{O}, 0.2 \%$ sodium thiopyruvate $\mathrm{H}_{2} \mathrm{O}$ or $0.2 \%$ cystine $\mathrm{HCl}$. Rats weighing approximately $90 \mathrm{~g}$ were used and the daily feed administration was $7 \mathrm{~g}$.

Experiment 3. The purpose of this experiment was to observe the effects of intraperitoneal injection of methionine, cysteine or hypotaurine on the concentrations of nonprotein-sulfhydryl and taurine, and fat content in the liver. Rats weighing $60 \mathrm{~g}$ were given $10 \%$ casein diet from 9 a.m. to 5 p.m., and injected intraperitoneally with a solution containing 0.2 mmoles of either glutamic acid, methionine, cysteine or hypotaurine at noon for 10 days. These treatments were carried out expecting that the ingestion of the diet synchronized with the excess of catabolites of sulfurcontaining amino acids in the animal. Rats were killed at $5 \mathrm{p} . \mathrm{m}$. on the last day. The liver was quickly removed and used for analysis.

\section{Analytical procedure}

Nonprotein-sulf hydryl (NP-SH) concentration in the liver was determined by the method of Sedlak and Lindsay. ${ }^{8}$ ) Taurine concentration in the liver was estimated by the modification ${ }^{3)}$ of the method of Sörbo. ${ }^{8)}$ The liver fat content was determined gravimetrically after ethyl ether extraction of the dried liver. The nitrogen in the urine was estimated by the semimicro-Kjeldahl method.

\section{RESULTS AND DISCUSSION}

Table I shows the results of experiment 1 . In all cases tested, the addition of methionine to the protein-free diet remarkably reduced the excretion of urinary nitrogen, but statistically speaking, the effect of the addition of $0.01 \%$ methionine was not significant. As to the mechanisms of this effect of methionine, it is obscure whether it is due to improvement of the reutilization of endogenous amino acids or reduction of catabolism of body proteins. However, this result is in agreement with those reported by many investigators. ${ }^{5,10 \sim 12)}$ While the addition of smaller amounts of methionine to the protein-free diet reduced the excretion of urinary nitrogen, the liver fat accumulation was not produced 
Table 1. Effect of Force-feeding of a Protein-free Diet Supplemented With Methionine on Liver Fat, Nonprotein Sulfhydryl,

TAURINe CONCENTration, and URINARY NITROGEN

\begin{tabular}{lccccc}
\hline & & Protein-free & $\begin{array}{c}+0.01 \% \\
\text { methionine }\end{array}$ & $\begin{array}{c}+0.05 \% \\
\text { methionine }\end{array}$ & $\begin{array}{c}+0.2 \% \\
\text { methionine }\end{array}$ \\
\hline No. of rats & & 6 & 6 & 6 & 6 \\
Body wt. change & $\mathrm{g} / 4$ days & $\left.-3.2 \pm 0.9^{a}\right)$ & $-2.2 \pm 0.7$ & $-1.7 \pm 0.5$ & $-2.2 \pm 0.3$ \\
Final body wt. & $\mathrm{g}$ & $112 \pm 2.5$ & $112 \pm 3.3$ & $112 \pm 3.3$ & $112 \pm 2.7$ \\
Liver wt. & $\mathrm{g}$ & $4.23 \pm 0.15^{\mathrm{A}}$ & $4.38 \pm 0.16^{\mathrm{AB}}$ & $4.65 \pm 0.20^{\mathrm{B}}$ & $5.15 \pm 0.07^{\mathrm{C}}$ \\
Liver nonprotein $\mathrm{SH}$ & $\mu \mathrm{mole} / \mathrm{g}$ & $1.14 \pm 0.05^{\mathrm{A}}$ & $1.33 \pm 0.09^{\mathrm{B}}$ & $2.47 \pm 0.42^{\mathrm{C}}$ & $7.97 \pm 0.26^{\mathrm{D}}$ \\
Liver taurine & $\mu \mathrm{mole} / \mathrm{g}$ & $2.31 \pm 0.15^{\mathrm{A}}$ & $2.26 \pm 0.11^{\mathrm{A}}$ & $3.07 \pm 0.23^{\mathrm{B}}$ & $3.85 \pm 0.18^{\mathrm{C}}$ \\
Liver fat & $\mathrm{mg} / \mathrm{g}$ dry liver & $164 \pm 12.8^{\mathrm{A}}$ & $143 \pm 7.6^{\mathrm{A}}$ & $147 \pm 15.6^{\mathrm{A}}$ & $248 \pm 18.6^{\mathrm{B}}$ \\
& $\mathrm{mg} / 100 \mathrm{~g}$ body wt. & $178 \pm 15.7^{\mathrm{A}}$ & $160 \pm 8.0^{\mathrm{A}}$ & $193 \pm 18.6^{\mathrm{A}}$ & $373 \pm 34.7^{\mathrm{B}}$ \\
Urinary nitrogen & $\mathrm{mg} / 2$ days & $51.7 \pm 4.5^{\mathrm{A}}$ & $42.1 \pm 3.0^{\mathrm{AB}}$ & $42.1 \pm 1.8^{\mathrm{B}}$ & $41.0 \pm 2.5^{\mathrm{B}}$ \\
\hline
\end{tabular}

a) S.E.

A BCD Means within line and with different superscript letters differ significantly $(P<0.05)$.

by the addition of methionine when the concentration was under $0.05 \%$. The addition of $0.2 \%$ methionine, however, clearly induced the liver fat accumulation and significantly increased the concentrations of NP-SH and taurine as compared with those of the other cases. In the previous study ${ }^{6}$ ) we suggested that increases in concentrations of NP-SH and taurine in the liver of rats given a low heated soybean flout or casein diet supplemented with sulfur-containing amino acids might reflect an excess of some catabolites of sulfurcontaining amino acids. The relationship was confirmed between changes in concentrations of sulfur-containing metabolites and fat content in the liver and those in the excretion of urinary nitrogen accompanied with different amounts of methionine added to the protein-free diet. So, it was considered that the addition of methionine to less than $0.05 \%$ was effective in the reduction of urinary nitrogen while addition of methionine to more than $0.05 \%$ was relatively too excessive to reduce urinary nitrogen, and that this excessive methionine or its metabolites might induce the liver fat accumulation.

The results of experiment 2 are given in Table II. The addition of $0.2 \%$ cystine $\mathrm{HCl}$ to the protein-free diet significantly decreased the excretion of urinary nitrogen, increased the concentrations of NP-SH and taurine, and induced the liver fat accumulation. These effects of addition of $0.2 \%$ cystine $\mathrm{HCl}$ were similar to those of the addition of $0.2 \%$

Table II. Effect of Force-feeding of a Protein-free Diet Supplemented With Sulfur-containing Compounds on Liver Fat, Nonprotein SUlfHYDRYL, TAURINE CONCENTRATION AND URINARY Nitrogen

\begin{tabular}{|c|c|c|c|c|c|}
\hline & Protein-free & $\begin{array}{c}+0.2 \% \\
\text { hypotaurine } \mathrm{s}\end{array}$ & $\begin{array}{l}+0.2 \% \text { cysteine } \\
\text { sulfinic acid } 2 \mathrm{H}_{2} \mathrm{O}\end{array}$ & $\begin{array}{c}+0.2 \% \\
\text { thiopyruvate }\end{array}$ & $\begin{array}{l}+0.2 \% \text { cystine } \\
2 \mathrm{H}_{2} \mathrm{O}\end{array}$ \\
\hline No. of rats & 6 & 6 & 6 & 6 & 6 \\
\hline Body wt. change $g / 4$ days & $-3.0 \pm 0.6^{a)}$ & $-2.2 \pm 0.6$ & $-2.5 \pm 0.7$ & $-3.3 \pm 0.6$ & $-1.8 \pm 0.7$ \\
\hline Final body wt. $\mathrm{g}$ & $95 \pm 1.6$ & $97 \pm 1.3$ & $97 \pm 1.3$ & $96 \pm 1.6$ & $99 \pm 2.3$ \\
\hline Liver wt. $\quad \mathrm{g}$ & $3.78 \pm 0.22$ & $3.82 \pm 0.09$ & $3.94 \pm 0.12$ & $3.65 \pm 0.04$ & $3.88 \pm 0.11$ \\
\hline Liver nonprotein $\mathrm{SH} \mu$ mole/g & $1.36 \pm 0.06^{4}$ & $1.25 \pm 0.02^{A}$ & $1.31 \pm 0.05 A$ & $1.26 \pm 0.02^{A}$ & $6.96 \pm 0.28^{B}$ \\
\hline Liver taurine $\quad \mu$ mole $/ \mathrm{g}$ & $1.99 \pm 0.24^{\mathrm{A}}$ & $2.78 \pm 0.17^{\mathrm{B}}$ & $2.20 \pm 0.17 \AA$ & $2.19 \pm 0.15^{\mathrm{A}}$ & $3.09 \pm 0.32^{\mathrm{B}}$ \\
\hline Liver fat mg/g dry liver & $102 \pm 10^{A}$ & $145 \pm 11^{\mathrm{b}}$ & $116 \pm 9 A$ & $111 \pm 8^{A}$ & $212 \pm 10^{\mathrm{C}}$ \\
\hline $\mathrm{mg} / 100 \mathrm{~g}$ body wt. & $108 \pm 10^{\mathrm{A}}$ & $153 \pm 12^{\mathrm{B}}$ & $126 \pm 9^{\mathrm{AB}}$ & $119 \pm 7^{A}$ & $262 \pm 21^{\mathrm{C}}$ \\
\hline Urinary nitrogen $\mathrm{mg} / 2$ days & $54.9=2.9^{A}$ & $60.6 \pm 3.7^{\mathrm{A}}$ & $52.9 \pm 2.8^{A}$ & $53.4 \pm 1.0^{\mathrm{A}}$ & $43.7 \pm 2.6^{\mathrm{B}}$ \\
\hline
\end{tabular}

a) S.E.

a) S.E.
$A B C$ Means within line and with different superscript letters differ significantly $(P<0.05)$. 
Table III. EfFect of Injection of Sulfur-containing Compounds on Liver Fat, Nonprotein Sulfhydryl and Taurine Concentration in Rats Fed a 10\% Casein Diet

\begin{tabular}{llcccc}
\hline & & Glutamic acid & Hypotaurine & Cysteine & Methionine \\
\hline \multicolumn{1}{c}{ Daily dose } & & 0.2 mmole & 0.2 mmole & 0.2 mmole & 0.2 mmole \\
No. of rats & & 5 & 5 & 5 & 5 \\
Body wt. gain & $\mathrm{g} / 9$ days & $6.8 \pm 1.6^{a}$ & $8.6 \pm 1.3$ & $7.4 \pm 0.8$ & $10.4 \pm 1.8$ \\
Food intake & $\mathrm{g} /$ day & $6.0 \pm 0.2$ & $6.1 \pm 0.3$ & $5.7 \pm 0.2$ & $6.2 \pm 0.3$ \\
Final body wt. & $\mathrm{g}$ & $64 \pm 5.0$ & $66 \pm 2.1$ & $65 \pm 2.7$ & $70 \pm 3.3$ \\
Liver wt. & $\mathrm{g}$ & $3.15 \pm 0.13^{\mathrm{A}}$ & $3.60 \pm 0.14^{\mathrm{B}}$ & $3.99 \pm 0.15^{\mathrm{B}}$ & $4.10 \pm 0.30^{\mathrm{B}}$ \\
Liver nonprotein SH & $\mu$ mole/g & $1.37 \pm 0.08^{\mathrm{A}}$ & $1.44 \pm 0.07^{\mathrm{A}}$ & $2.95 \pm 0.40^{\mathrm{B}}$ & $4.11 \pm 0.21^{\mathrm{C}}$ \\
Liver taurine & $\mu$ mole/g & $2.22 \pm 0.17^{\mathrm{A}}$ & $7.02 \pm 0.66^{\mathrm{BC}}$ & $7.15 \pm 0.35^{\mathrm{BC}}$ & $8.15 \pm 0.57^{\mathrm{C}}$ \\
Liver fat & $\mathrm{mg} / \mathrm{g}$ dry liver & $62 \pm 5.1^{\mathrm{A}}$ & $90 \pm 10.6^{\mathrm{B}}$ & $105 \pm 5.5^{\mathrm{C}}$ & $92 \pm 11.0^{\mathrm{BC}}$ \\
& $\mathrm{mg} / 100 \mathrm{~g}$ body wt. & $91 \pm 8.1^{\mathrm{A}}$ & $133 \pm 14.7^{\mathrm{B}}$ & $192 \pm 9.3^{\mathrm{C}}$ & $166 \pm 22.6^{\mathrm{BC}}$ \\
\hline
\end{tabular}

a) S.E.

ABC Means within line and with different superscript letters differ significantly $(P<0.05)$.

methionine in the previous experiment. The addition of $0.2 \%$ cystine sulfinic acid or thiopyruvate, however, did not produce any changes in the liver fat content, concentrations of NP-SH and taurine in the liver and the excretion of urinary nitrogen. On the other hand, the addition of $0.2 \%$ hypotaurine to the protein-free diet significantly increased the liver fat content, although this increased fat content was less than that caused by the addition of $0.2 \%$ cystine $\mathrm{HCl}$. Taurine concentration but not NP-SH concentration was also increased. This finding might support the possibility that the excess of some catabolites of sulfur-containing amino acid is one of the factors which cause the liver fat accumulation. As cysteine sulfinic acid is a precursor of hypotaurine, ${ }^{13,14}$ these results raise the question why the addition of cysteine sulfinic acid to the protein-free diet did not produce the liver fat accumulation. We suppose the compound might be easily oxidized to cysteic acid in the gastrointestinal tract, since the oral administration of cysteine sulfinic acid did not increase the concentration of taurine in the liver (Table II). It was also observed that the addition of cysteic acid to the protein-free diet did not affect the liver fat content. ${ }^{5)}$ The intraperitoneal injection of small amounts of cysteine sulfinic acid significantly increased the concentration of taurine in the liver, but did not affect the liver fat content. It remarkably reduced the food intake and was strongly toxic for animals.*

Table III shows the results of experiment 3 . In all cases studied, there were statistically no differences in the body weight gain and food intake, but the body weight gain of rats injected methionine tended to be higher than that of rats injected with the other compounds. The injection of either cysteine or methionine significantly increased the liver fat content, and NP-SH and taurine concentrations as compared with that of glutamic acid, which the control group received. The injection of hypotaurine increased the liver fat content and taurine concentration in the liver, without any changes in the NP-SH concentration. The effects of injection of these sulfur-containing compounds on the concentrations of sulfurcontaining metabolites and fat content were similar to those of oral administration of these compounds as described in the previous experiments. The liver fat accumulation associated with changes in the concentrations of NP-SH and taurine in the liver was induced by either the administration of a low casein diet supplemented with sulfur-containing amino acids or injection of them to rats fed a low casein diet. These findings support the possibility that the excess of some catabolites of sulfurcontaining amino acids might be one of the factors which cause the liver fat accumulation. It is not clear yet, however, whether or not the excess of these catabolites plays an im* Unpublished observation. 
portant role in the liver fat accumulation of rats fed a low casein diet supplemented with sulfur-containing amino acids. In view of this possibility, results of experiments 2 and 3 raised the question why the liver fat accumulation caused by the administration of sulfur-containing amino acids was more remarkable than that caused by the administration of hypotaurine, which was considered a more directly effective compound in the liver fat accumulation than sulfur-containing amino acids. In this regard we suppose that the liver fat accumulation caused by the administration of sulfur-containing amino acids might be induced by other factors besides excess of their catabolites. But in either oral or intraperitoneal administration of catabolites of sulfurcontaining amino acids, before they reached the liver, which is the major site to catabolize sulfur-containing amino acids, ${ }^{15,16)}$ most of them were considered to be easily and spontaneously oxidized to noneffective catabolites, taurine or cysteic acid, for the liver fat accumulation. In any case, the mechanism of liver fat accumulation caused by catabolites of cysteine are unknown. These problems are under investigation in our laboratory.

Acknowledgement. The authors wish to thank Central Research Laboratory of Ajinomoto Co., Ltd. for the research fund and for supplying of cysteine sulfinic acid, sodium thiopyruvate, and hypotaurine.

\section{REFERENCES}

1) A. E. Harper, Amer. J. Clin. Nutr., 6, 242 (1958).

2) A. Yoshida and A. E. Harper, J. Biol. Chem., 235, 2568 (1960).

3) A. Yoshida, K. Ashida and A. E. Harper, Nature, 189, 917 (1961).

4) A. Yoshida and K. Ashida, Agr. Biol. Chem., 26, 56 (1962).

5) T. Kimura, K. Ebihara and A. Yoshida, ibid., 39, 651 (1975).

6) T. Kimura, T. Suzuki, M. Ishikawa and A. Yoshida, ibid., 40, 535 (1976).

7) A. E. Harper, J. Nutr., 68, 405 (1959).

8) J. Sedlak and R. H. Lindsay, Anal. Biochem., 25, 192 (1968).

9) B. Sörbo, Clin. Chem. Acta, 6, 87 (1961).

10) M. Brush, W. Willman and P. P. Swanson, $J$. Nutr., 33, 389 (1947).

11) J. B. Allison, J. A. Anderson and R. D. Seeley, ibid., 33, 389 (1947).

12) A. Yoshida and K. Moritoki, Nutr. Report Inter., 9, 159 (1974).

13) M. Tabachnik and H. Tarver, Arch. Biochem. Biophys., 56, 115 (1965).

14) F. Chapeville and P. Fromagot, Biochim. Biophys. Acta, 17, 275 (1955).

15) L. Ewetz and B. Sörbo, ibid., 128, 296 (1966).

16) K. Yamaguchi, S. Sakakibara, J. Asamizu and I. Ueda, Biochim. Biophys. Acta, 297, 48 (1973). 